\title{
Supporting Information for Fluoride in the SEI Stabilizes the Li Metal Interface in Li-S Batteries with Solvate Electrolytes
}

Skyler D. Ware,$^{\dagger}$ Charles J. Hansen, ${ }^{\dagger}$ John-Paul Jones, ${ }^{\ddagger}$ John Hennessy, ${ }^{\ddagger}$ Ratnakumar V. Bugga, ${ }^{\ddagger}$ and Kimberly A. See ${ }^{* \dagger}$

$\dagger$ Division of Chemistry and Chemical Engineering, California Institute of Technology, Pasadena, California 91125, United States

$\ddagger$ Jet Propulsion Laboratory, California Institute of Technology, Pasadena, CA 91109, United States

E-mail: ksee@caltech.edu 


\section{Supporting Information}
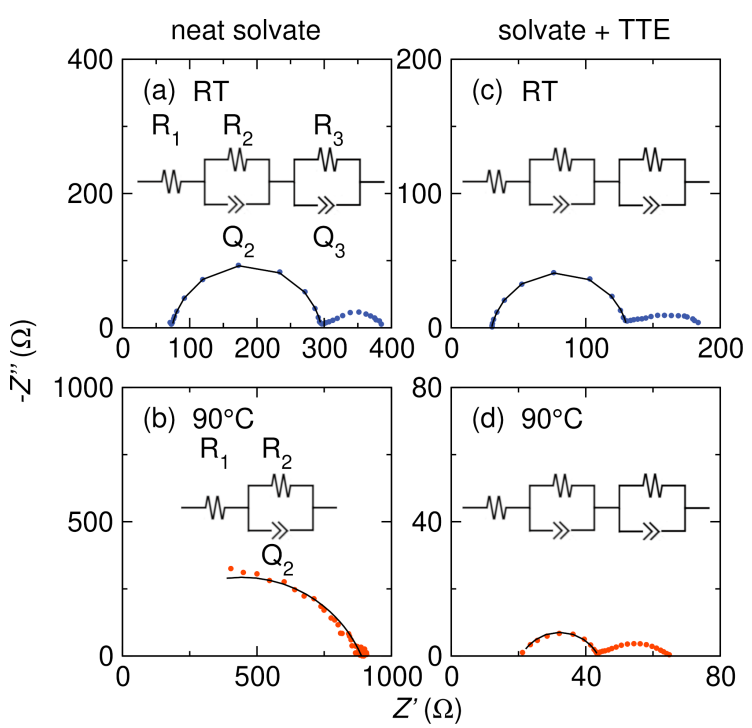

Figure S1: Fits to the high frequency feature of the final collected EIS spectra of Li-Li symmetric cells prepared with (a) neat solvate electrolyte at room temperature, (b) neat solvate electrolyte at $90{ }^{\circ} \mathrm{C}$, (c) solvate + TTE electrolyte at room temperature, and (d) solvate + TTE electrolyte at $90{ }^{\circ} \mathrm{C}$. EIS data was collected from $10^{6}-10^{-6} \mathrm{~Hz}(\mathrm{a}, \mathrm{c}, \mathrm{d})$ or $10^{6}-1 \mathrm{~Hz}$ (b) at 10 points per decade, with a $10 \mathrm{mV}$ amplitude, continuously for $47 \mathrm{~h}$.
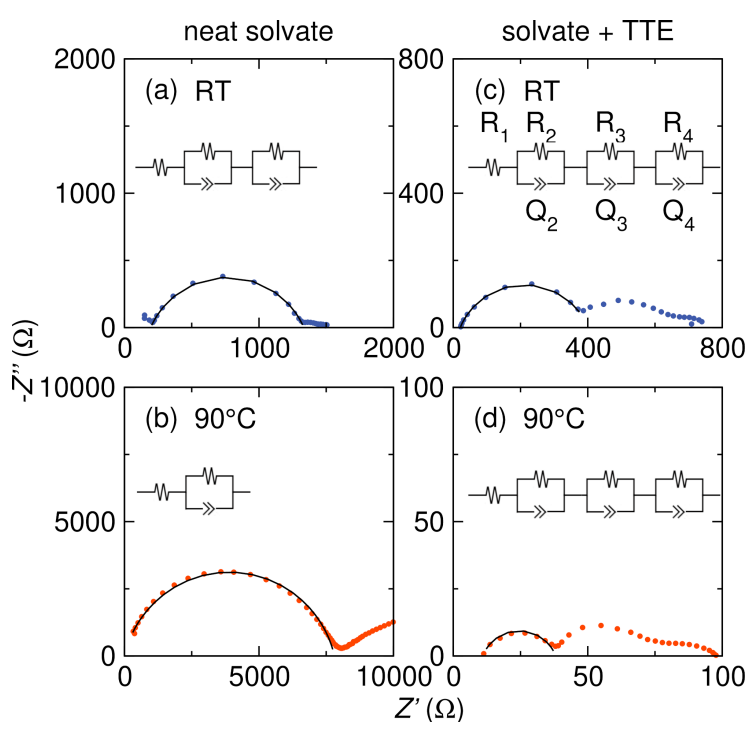

Figure S2: Fits to the high frequency feature of the final collected EIS spectra of $\mathrm{AlF}_{3}$-coated Li symmetric cells prepared with (a) neat solvate electrolyte at room temperature, (b) neat solvate electrolyte at $90{ }^{\circ} \mathrm{C}$, (c) solvate + TTE electrolyte at room temperature, and (d) solvate + TTE electrolyte at $90^{\circ} \mathrm{C}$. EIS data was collected from $10^{6}-10^{-6} \mathrm{~Hz}(\mathrm{a}, \mathrm{c}, \mathrm{d})$ or $10^{6}-1 \mathrm{~Hz}$ (b) at 10 points per decade, with a $10 \mathrm{mV}$ amplitude, continuously for $47 \mathrm{~h}$. 


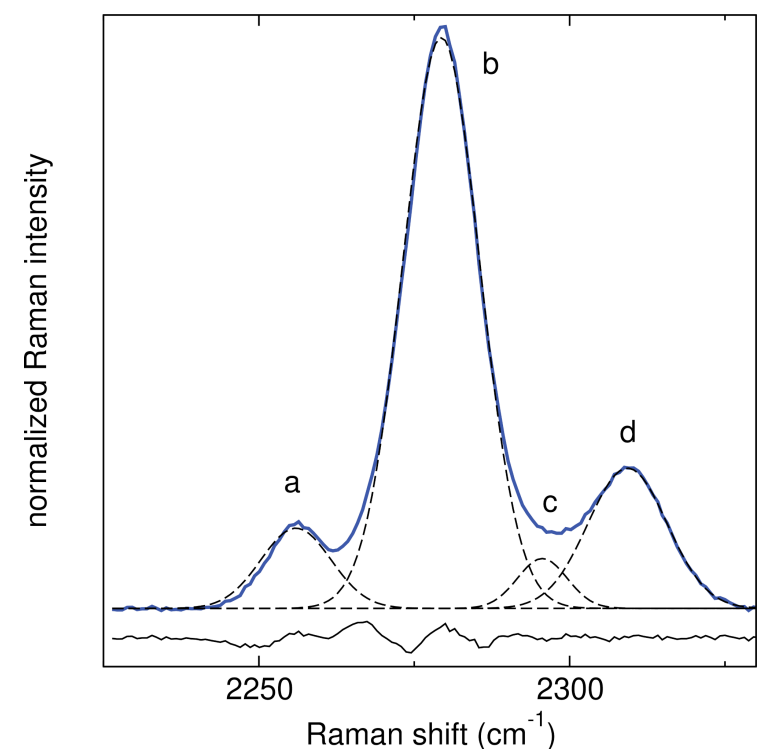

Figure S3: Fits to the room temperature Raman spectrum of $\mathrm{MeCN}$ modes in the neat solvate electrolyte.

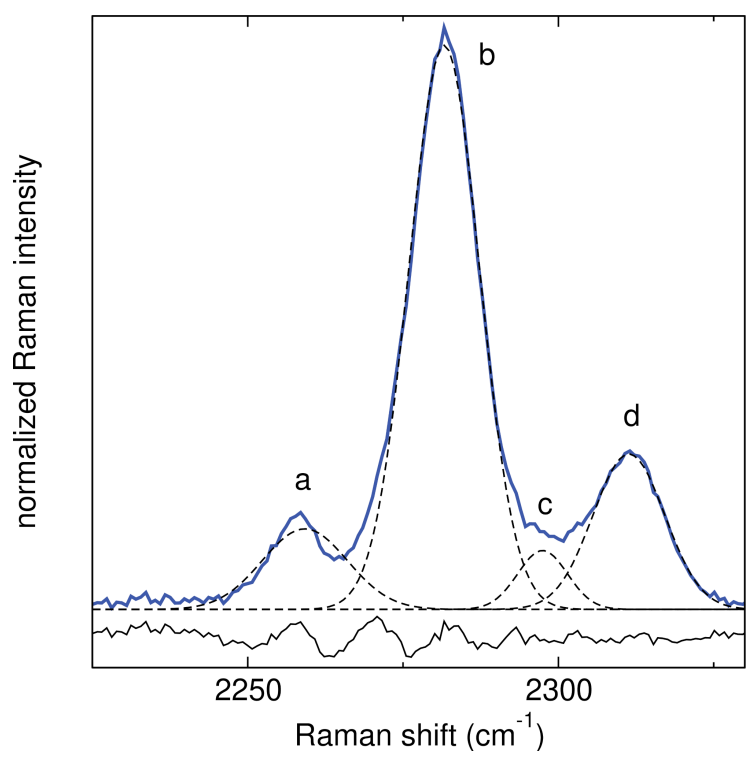

Figure S4: Fits to the room temperature Raman spectrum of MeCN modes in the solvate + TTE electrolyte. 


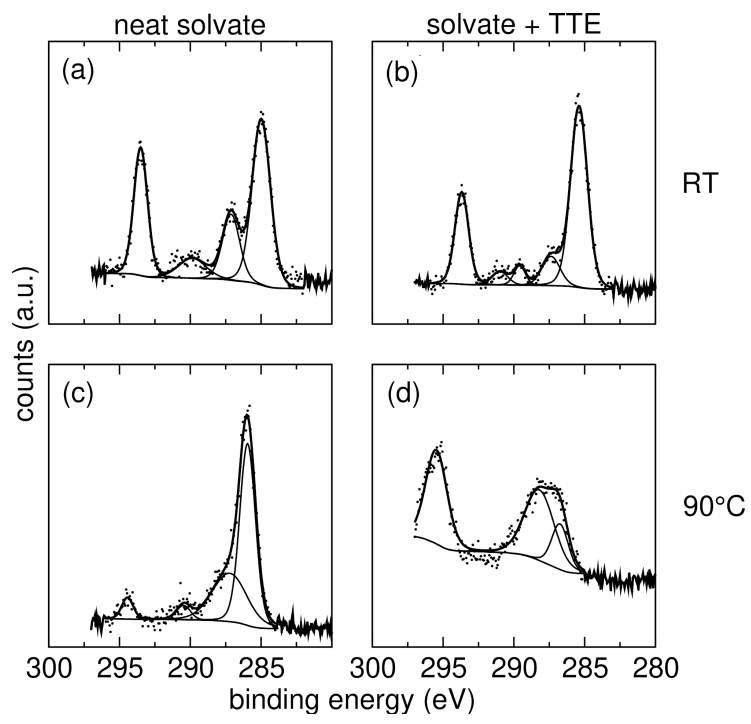

Figure S5: The C 1s spectra of Li metal with reacted with (a) neat solvate electrolyte at RT, (b) solvate + TTE electrolyte at RT, (c) neat solvate electrolyte at $90{ }^{\circ} \mathrm{C}$, and (d) solvate + TTE electrolyte at $90{ }^{\circ} \mathrm{C}$. The lowest binding energy peak in each spectrum was calibrated to $285 \mathrm{eV}$.

Table S1: Peak assignments of the X-ray photoelectron spectra of Li metal reacted with the neat solvate electrolyte at RT and $90{ }^{\circ} \mathrm{C}$

\begin{tabular}{lll} 
Figure & Peak binding energy $(\mathbf{e V})$ & Assignment \\
\hline $4 \mathrm{a}$ & 532.5 & $\mathrm{Li}_{2} \mathrm{SO}_{4}$ \\
& 533.7 & $\mathrm{Li}_{2} \mathrm{O}$ \\
$4 \mathrm{~b}$ & 400.1 & adsorbed MeCN \\
$4 \mathrm{c}$ & 685.7 & $\mathrm{LiF}$ \\
& 689.4 & $\mathrm{TFSI}$ \\
$4 \mathrm{~d}$ & 531.5 & $\mathrm{Li}_{2} \mathrm{CO}_{3}$ \\
& 532.5 & $\mathrm{Li}_{2} \mathrm{SO}_{4}$ \\
$4 \mathrm{e}$ & 399.4 & $\mathrm{CN}$ group \\
$4 \mathrm{f}$ & 685.7 & $\mathrm{LiF}$ \\
& 689.4 & $\mathrm{TFSI}$
\end{tabular}


Table S2: Peak assignments of the X-ray photoelectron spectra of Li metal reacted with the solvate + TTE electrolyte at RT and $90{ }^{\circ} \mathrm{C}$

\begin{tabular}{lll} 
Figure & Peak binding energy (eV) & Assignment \\
\hline $5 \mathrm{a}$ & 532.2 & $\mathrm{Li}_{2} \mathrm{SO}_{4}$ \\
& 533.4 & $\mathrm{Li}_{2} \mathrm{O}$ \\
& 534.6 & impurity \\
$5 \mathrm{~b}$ & 400 & adsorbed MeCN \\
$5 \mathrm{c}$ & 685.4 & $\mathrm{LiF}$ \\
& 689.1 & $\mathrm{TTE}$ or TFSI \\
$5 \mathrm{~d}$ & 533.1 & $\mathrm{SO}_{4}$ \\
& 531.5 & $\mathrm{Li}_{2} \mathrm{CO}_{3}$ \\
$5 \mathrm{e}$ & 399.9 & $\mathrm{CN}_{\text {group }}$ \\
$5 \mathrm{f}$ & 685.6 & $\mathrm{LiF}$ \\
& 686.9 & $\mathrm{TTE}$ or TFSI \\
& 688.9 & $\mathrm{TFSI}$ \\
& 690.4 & $\mathrm{TTE}$
\end{tabular}

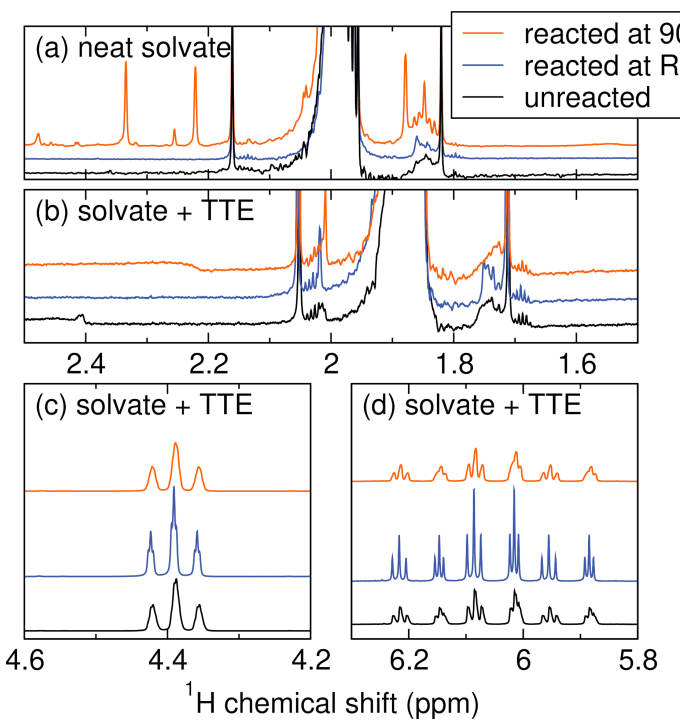

Figure S6: ${ }^{1} \mathrm{H}-\mathrm{NMR}$ spectra of (a) the neat solvate electrolyte and (b)-(d) the solvate + TTE electrolyte before and after reaction with $\mathrm{Li}$ metal at room temperature and $90{ }^{\circ} \mathrm{C}$. New peaks appear after reaction between the neat solvate electrolyte and $\mathrm{Li}$ at $90{ }^{\circ} \mathrm{C}$, indicating electrolyte decomposition. No decomposition is observed after reaction between the solvate + TTE electrolyte at either temperature. The minor shifts in (b) at $1.75 \mathrm{ppm}$ and $2.01 \mathrm{ppm}$ are likely related to negligible changes in coordination structure after heating rather than electrolyte decomposition. The excess deuterated MeCN added as a lock may also affect electrolyte speciation but does not contribute to decomposition. 

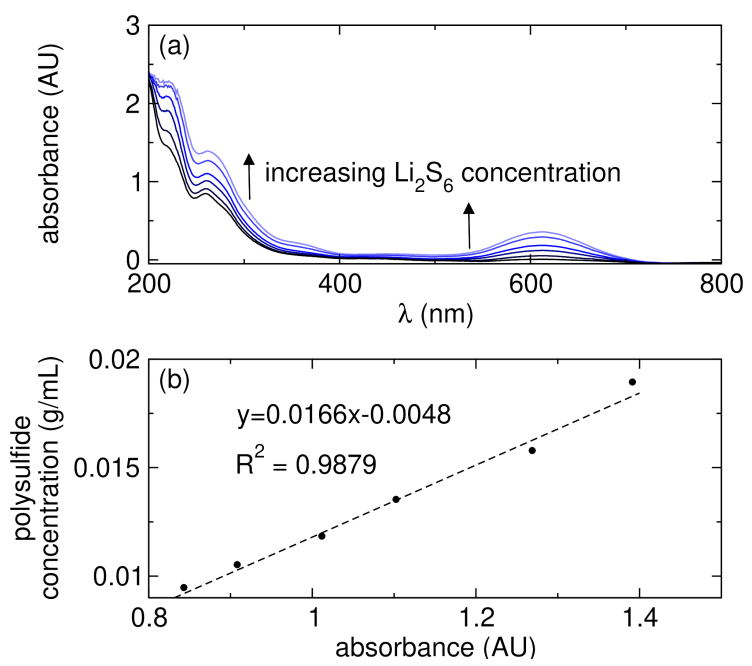

Figure S7: (a) UV-Visible spectra of Li polysulfides in MeCN at RT, with the arrow indicating increasing polysulfide concentration. Peaks corresponding to $S_{8}(261 \mathrm{~nm})$ and $S_{3}{ }^{-}(612 \mathrm{~nm})$ are observed due to several disproportionation reactions during polysulfide dissolution. (b) The intensity of the $261 \mathrm{~nm}$ peak is plotted against the Li polysulfide concentration in each standard solution to derive a Beer's Law relationship.

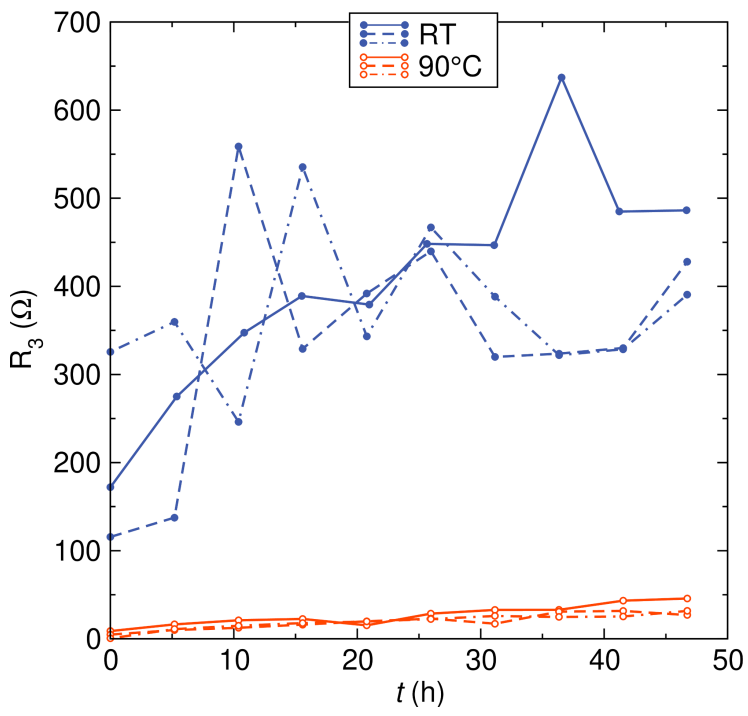

Figure S8: Charge transfer resistance, $\mathrm{R}_{3}$, from the mid-frequency EIS feature of three replicate $\mathrm{AlF}_{3}$-coated $\mathrm{Li}$ symmetric cells with solvate $+\mathrm{TTE}$ electrolyte at room temperature and $90{ }^{\circ} \mathrm{C} . \mathrm{R}_{3}$ increases at both temperatures similarly to $R_{2}$. An increase in $R_{3}$ may indicate reactivity at the $\mathrm{Li} / \mathrm{AlF}_{3}$ interface. 


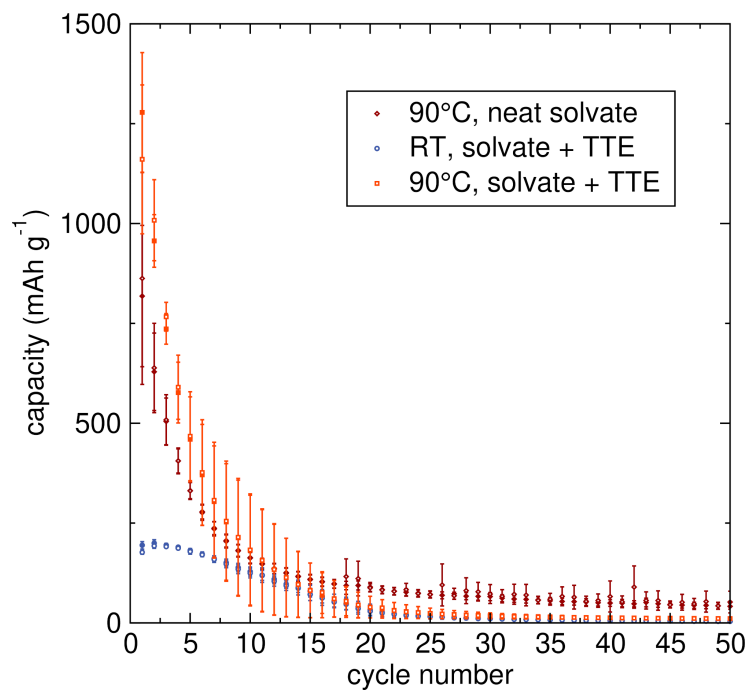

Figure S9: Capacity fade over 50 cycles in $\mathrm{AlF}_{3}$-coated $\mathrm{Li}-\mathrm{S}$ cells prepared with both the neat solvate electrolyte and the solvate + TTE electrolyte. Cells cycled at high temperatures yield higher initial capacity but more rapid capacity fade than cells cycled at room temperature. All cells were cycled at $\mathrm{C} / 10$ rate.

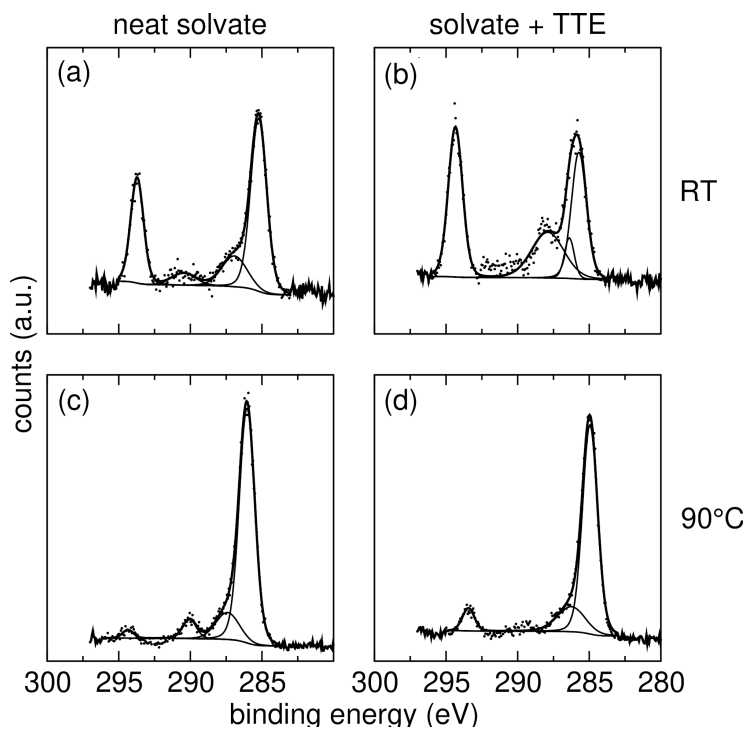

Figure S10: The $\mathrm{C}$ 1s spectra of $\mathrm{AlF}_{3}$-coated Li metal with reacted with (a) neat solvate electrolyte at RT, (b) solvate + TTE electrolyte at RT, (c) neat solvate electrolyte at $90{ }^{\circ} \mathrm{C}$, and (d) solvate + TTE electrolyte at $90{ }^{\circ} \mathrm{C}$. The lowest binding energy peak in each spectrum was calibrated to 285 eV. 
Table S3: Peak assignments of the $\mathrm{X}$-ray photoelectron spectra of $\mathrm{AlF}_{3}$-coated Li metal reacted with the neat solvate electrolyte at RT and $90{ }^{\circ} \mathrm{C}$

\begin{tabular}{lll} 
Figure & Peak binding energy $(\mathbf{e V})$ & Assignment \\
\hline $11 \mathrm{a}$ & 532.3 & $\mathrm{Li}_{2} \mathrm{SO}_{4}$ \\
& 533.6 & $\mathrm{Li}_{2} \mathrm{O}$ \\
$11 \mathrm{~b}$ & 400.1 & adsorbed $\mathrm{MeCN}$ \\
$11 \mathrm{c}$ & 689.2 & $\mathrm{TFSI}$ \\
& 685.4 & $\mathrm{LiF}$ \\
$11 \mathrm{~d}$ & 531.4 & $\mathrm{Li}_{2} \mathrm{CO}_{3}$ \\
& 532.3 & $\mathrm{Li}_{2} \mathrm{SO}_{4}$ \\
& 533.6 & $\mathrm{Li}_{2} \mathrm{O}$ \\
$11 \mathrm{e}$ & 399.4 & $\mathrm{CN}$ group \\
$11 \mathrm{f}$ & 689.2 & $\mathrm{TFSI}$ \\
& 685.4 & $\mathrm{LiF}$
\end{tabular}

Table S4: Peak assignments of the $\mathrm{X}$-ray photoelectron spectra of $\mathrm{AlF}_{3}$-coated Li metal reacted with the solvate + TTE electrolyte at RT and $90{ }^{\circ} \mathrm{C}$

\begin{tabular}{lll} 
Figure & Peak binding energy $(\mathbf{e V})$ & Assignment \\
\hline $12 \mathrm{a}$ & 532.5 & $\mathrm{Li}_{2} \mathrm{SO}_{4}$ \\
& 533.6 & $\mathrm{Li}_{2} \mathrm{O}$ \\
& 534.6 & impurity \\
$12 \mathrm{~b}$ & 400.1 & adsorbed MeCN \\
$12 \mathrm{c}$ & 689.2 & $\mathrm{TFSI}$ \\
& 685.4 & $\mathrm{LiF}$ \\
& 685.9 & $\mathrm{LiF}$ \\
$12 \mathrm{~d}$ & 532.5 & $\mathrm{Li}_{2} \mathrm{SO}_{4}$ \\
& 533.7 & $\mathrm{Li}_{2} \mathrm{O}$ \\
$12 \mathrm{e}$ & 400.1 & $\mathrm{adsorbed} \mathrm{MeCN}$ \\
$12 \mathrm{f}$ & 689.2 & $\mathrm{TFSI}$ \\
& 685.4 & $\mathrm{LiF}$
\end{tabular}

